\title{
DEFICIÊNCIA VISUAL: MAIS SENSÍVEL QUE UM OLHAR
}

\author{
Alessandra dos Santos Oliveira ${ }^{1}$; Laura de Carvalho ${ }^{2}$ \\ ${ }^{1}$ Graduanda em Psicologia, pela Universidade do Oeste Paulista em Presidente Prudente SP. lekapsico@uol.com.br. ${ }^{2}$ \\ Doutoranda em Psicologia, área de concentração Avaliação Psicológica pela Universidade São Francisco. Docente de \\ Graduação em Psicologia na Universidade do Oeste Paulista-Presidente Prudente/SP. laura carvalho@uol.com.br
}

\begin{abstract}
RESUMO:
O trabalho apresenta uma experiência de estágio na Associação Filantrópica de Proteção aos Cegos de Presidente Prudente. Este consistiu na aplicação dos conhecimentos teóricos adquiridos durante a formação acadêmica de Psicologia, a fim de possibilitar uma prestação de serviços à comunidade. Os encontros do grupo operativo aconteceram na sede da instituição sob a coordenação de quatro estudantes de Psicologia com a supervisão de uma docente da área de psicologia escolar. Participaram do grupo cerca de 12 deficientes visuais com idade entre 30 a 70 anos, de ambos os sexos. Durante os encontros houve a preocupação em incentivar os deficientes visuais a utilizar suas capacidades e habilidades distintas, trabalhando com estes de forma global e diversificada. O projeto de extensão buscou proporcionar diversas atividades que estimulassem os demais órgãos do sentido. Trabalhou-se também, com temas relevantes e atuais, buscando conscientizá-los de sua cidadania, em especial sobre o tema inclusão social. Priorizou-se acompanhar a evolução dos encontros por meio de linguagem acessível, visto que os deficientes visuais que participaram do grupo eram compostos por pessoas semi-analfabetas e de classe social de baixa renda. Os temas foram introduzidos sempre considerando a compreensão dos mesmos.
\end{abstract}

Palavras-chave: deficiência visual, inclusão social, estimulação.

\section{VISUAL DEFICIENCY: MORE SENSITIVE THAN A GLANCE}

\begin{abstract}
The present work shows the experience of an intern group that carried out a project at the Philanthropic Association for Assintance to the Blind in Presidente Prudente (Associação Filantrópica de Proteção aos cegos de Presidente Prudente). It contains the application of the knowledge we acquired with the academic studies of Psichology in college and it intends to offer another service to the community. Our group used to gather at the office of the institution under the management of four students of Psichology supervised by a Professor. The study group consisted of twelve visually challenged people to use their special abilities and skills. They were always supported and given global attention. This extension project aimed to give several and diversified activities to the study group in order to stimulate other perception organs. Relevant and interesting themes were selected to be worked and they helped the study group to become aware of their citizenship. Social inclusion was specially literate and they belong to a class of low income. Effort was made to introduce the themes in an easy way so that they could understood.
\end{abstract}

Key words: visual deficiency, social inclusion, stimulation 


\section{INTRODUÇÃO}

MACIEL (2000, p. 54) enfatiza que:

"O princípio fundamental da sociedade inclusiva é o de que todas as pessoas portadoras de deficiência devem ter suas necessidades especiais atendidas. $\dot{E}$ no atendimento das diversidades que se encontra a democracia".

Este artigo relata uma experiência de projeto de extensão em uma associação voltada para a socialização dos deficientes visuais. O projeto iniciou-se no ano de 2003 e consistiu na aplicação dos conhecimentos teóricos adquiridos ao longo da formação acadêmica de Psicologia, a fim de possibilitar uma prestação de serviços à comunidade.

Dentre os conhecimentos teóricos pesquisados e adquiridos para o trabalho com o grupo o tema inclusão foi um dos mais discutidos por ter suscitado maior interesse entre os participantes.

Percebe-se desta forma que, a inclusão social em relação a qualquer tipo de deficiência vem ganhando cada vez mais espaço na sociedade. Mas, para incluir precisamos primeiramente conhecer a deficiência e procurar descobrir quais os tipos de necessidades o sujeito possui de acordo com suas limitações e capacidades.

Neste aspecto, reconhece-se como de suma relevância a busca de informação e conhecimento sobre o tema do presente artigo.

\subsection{Evolução sobre o conceito inclusão}

Para compreendermos a
situação atual dos portadores de deficiência quanto ao aspecto de inclusão, devemos ter em mente a história da exclusão social em relação a qualquer tipo de deficiência e sua constante busca de tratamento igualitário e humanizado.

Durante as Idades Antiga e Média qualquer diferença (física, mental, dentre outras) que o indivíduo apresentava era atribuída a perturbações de demônios, que se apossavam do indivíduo.

Nesta perspectiva, COLEMAN (1969, p. 33-34) afirma que:

"A decisão quanto ao fato
de o paciente estar
"possesso" por bons ou
maus espíritos dependia de
seus sintomas (...) quase
todos os possessos eram
considerados como obra de
maus espíritos sobretudo
quando o paciente ficava
agressivo (...) Em tais casos
faziam-se todos os esforços
para livrar o paciente do
mau espírito."

A pessoa era percebida como alguém que estava recebendo um castigo divino, sendo o culpado e responsável por seu próprio desajustamento. $O$ tratamento oferecido aos doentes mentais era desumano, incluindo violência (espancamentos, prisões, dentre outros) e a utilização de técnicas não científicas.

Neste contexto TELFORD e SAWREY postulam que:

"As concepções précientíficas das origens e natureza das formas mais extremas de desvio no desenvolvimento e aberração comportamental 
tendiam a ser de ordem sobrenatural e mística. Mais tarde os deficientes foram encarados como categorias isoladas de seres humanos" (1988, p.39-40).

$\mathrm{Na}$ era pré-científica, o deficiente visual era percebido como um vidente (sagrado) ou alguém que recebeu um dos piores castigos divinos, o de ter que ficar pra sempre na escuridão. Desta forma, o tratamento dispensado a estes podia variar bastante.

FOUCAULT (2002), investigando a história da loucura, nos mostra que, entre os séculos XIV ao XVII, a única forma de lidar com o indivíduo diferenciado era a exclusão contínua, isto é, excluíam de alguma forma estas pessoas do convívio social. Isto acontecia porque o modelo médico e os valores éticos encontravam-se fortemente cristalizados.

$\mathrm{Na}$ era da exclusão, retiravam-se os indivíduos indesejados da sociedade por meio de prisão, envio em embarcações marinhas e em último caso matava-se.

O mesmo autor assinala que 0 indivíduo excluído era aquele diferente de qualquer espécie. Podia ser o louco, deficiente, vagabundos, mendigos, dentre outros.

AMARILIAN (1986, p. 2) afirma que após a época da exclusão adveio o início do atendimento assistencial, ou seja, da segregação no final da Idade Medieval.

Contudo, nesta época a
preocupação não estava voltada às
necessidades dos deficientes, mas sim a
segurança da sociedade. A diferença
sempre incomodou e as pessoas não
queriam manter contato com a mesma.

Ainda segundo a autora (1986, p. 2), o advento do Renascimento e a valorização do conhecimento científico colaboraram para um melhor tratamento aos indivíduos indesejados.

Assim, houve rejeição aos maus tratos, até então oferecidos, e um novo olhar, mais humano começou a brotar em relação às diferenças.

A trajetória das pessoas portadoras de deficiência é longa e somente no século XX é que se utilizou da prática de integração social.

De acordo com SASSAKI (1999, p. 1) "no Brasil a preocupação em criar instituições especializadas ocorreu somente na década de 60 ". No final desta década, começou o movimento de inclusão dos indivíduos portadores de deficiência planos sociais gerais.

Portanto devemos considerar que o termo inclusão social é relativamente novo em nossa realidade e suas práticas ainda estão em fase de transição, visto que muitas vezes observa-se o movimento de integração e não de inclusão propriamente dito. Em geral, compreende-se o que significa inclusão, mas esta compreensão não se vivencia nas relações do cotidiano, ou seja, na prática.

\subsection{Integração X Inclusão}

SASSAKI (1997) afirma que em uma sociedade são observadas diversas fases no que se refere às práticas sociais: exclusão social, atendimento segregado, integração social e inclusão social e que essas podem ocorrer simultaneamente. Para o autor de acordo com a época em 
que estão inseridos tanto os conceitos se modificam como o tratamento dispensado aos portadores de deficiência.

$\mathrm{Na}$ atualidade a indiferenciação entre os significados específicos dos processos de inclusão e integração, além de causar confusão, contribui para manutenção e vigência do paradigma tradicional de serviços, e as instituições, embora acreditem exercer a práxis inclusiva, continuam a mantê-lo.

Os termos apesar de conter significados semelhantes, estão sendo empregados para expressar situações de tratamento diferentes, e tem por detrás posicionamentos divergentes, ou seja, interesses que se chocam, para a consecução de suas metas.

O autor SASSAKI (1997) aponta que a integração é um processo de normalização que encaixa os indivíduos deficientes a um padrão dito "normal", só que em outro espaço. A integração conseguiu inserir o portador de deficiência na sociedade, mas sua prática reflete que ele se ajuste ao sistema atual.

A integração é uma forma condicional de inserção que vai depender apenas do ajustamento do indivíduo, ou seja, do nível de sua capacidade de adaptação na sociedade ou mesmo em instituições especializadas. Trata-se de uma alternativa em que tudo se mantém e nada se questiona do esquema em vigor. Portanto, no modo asilar ocorre à exclusão social e a integração na instituição psiquiátrica. Já a inclusão institui a inserção de uma forma mais radical, completa e sistemática, pois a mudança deve partir de toda a sociedade. $\begin{array}{cccc} & \text { MACIEL } & (2001) \text { compara a } \\ \text { inclusão com o oferecimento de }\end{array}$ oportunidades, igualdade social em todos os âmbitos, e enfim, com a interação mútua entre todas as pessoas sem distinção.

Quando pensamos e agimos a favor da inclusão social, não depositamos a responsabilidade para que ela ocorra apenas no indivíduo, mas todo o contexto social tem um papel preponderante para que esta aconteça de fato. Entretanto, na maioria das vezes observa-se a ocorrência do fenômeno de integração e não de inclusão social. Desta forma, para que ocorra a inclusão são necessárias mudanças e adaptações de todo o contexto social.

1.3

\section{O indivíduo deficiente visual e suas implicações.}

Segundo ROSADAS a pessoa que possui qualquer tipo de diferença sofre algum tipo de discriminação e preconceito pela sociedade.

“A idade a cor da pele, a
diferença social, a diferença
física ou mesmo
comportamental têm sido,
com freqüência, marca em
nossa sociedade, servindo
essas pessoas ao abuso de
poder, ou ao livre arbítrio".
(1994, p. 9).

DAVIDOFF (2001) reconhece a deficiência visual como uma das deficiências físicas mais limitantes que existem. Para a autora, a visão colabora para que o indivíduo consiga apreender $\mathrm{o}$ mundo e proporciona a capacidade de captar os estímulos sensoriais que serão 
primordiais para sua relação com os objetos e pessoas.

A visão permite ao indivíduo adquirir o conhecimento do mundo, ou seja, através de seus olhos ele capta estímulos sensoriais que são primordiais para sua relação com objetos, pessoas, situações e sua vida social em geral.

Desta forma, o deficiente visual sofre limitações ao relacionar-se com o mundo externo. Durante toda sua vida o excepcional encontra dificuldades, pois necessita da autoconfiança, senso e equilíbrio que somente poderão ser atingidos através da colaboração, paciência e empatia das outras pessoas com as quais convive.

ROSADAS (1994) enfatiza que para a sociedade descobrir o que é bom para o deficiente visual é preciso primeiramente compreender como este é e do que necessita, só assim poderemos melhor atendê-los e contribuir com o oferecimento de atividades equilibradas e destinadas a eles.

Contudo, esta compreensão só será real se houver em primeiro lugar a aceitação de sua condição, ou seja, de suas capacidades e limitações na sociedade.

Para SILVA (2004), o preconceito gerado pela falta de conhecimento sobre o assunto é o grande responsável pela marginalização e exclusão em que ainda vivem os deficientes visuais. Infelizmente, muitas vezes, o preconceito é sentido e gerado pela própria família, que é rodeada por constrangimentos e vergonha.

Com a extinção do preconceito o indivíduo deficiente visual juntamente com sua família terá maiores possibilidades de buscar alternativas que facilitem suas relações, melhorando sua qualidade de vida. Com certeza esta nova postura frente às dificuldades irá colaborar para que o deficiente construa uma imagem positiva de si desde a infância. Somente a partir da aceitação da deficiência é que se pode falar e agir em prol da inclusão social.

Atualmente busca-se um movimento de inclusão, mas ainda não conseguimos vivenciá-lo. Compreendemos o seu significado na teoria, mas este se encontra muito distante da realidade social em que vivemos em nosso cotidiano.

A família tem um papel primordial no que se refere à inclusão social do deficiente visual.

Sobre este aspecto ROSADAS (1994) afirma que a família deve possuir persistência, resistência e confiança, já que o resultado positivo com os deficientes visuais podem não aparecer imediatamente.

Segundo TRUGILLO (2004), a reação inicial da família dependerá em muitos casos do tipo de informação adquirida. Assim, dependerá da forma como ela é apresentada e de como a informação é transmitida. É grande a importância destes aspectos, visto que podem determinar a aceitação desta criança no seio familiar.

Assim, a família contribui com a evolução do deficiente visual quando persiste e acredita que este se estimulado pode se desenvolver dentro de suas capacidades.

Em relação ao papel da família neste contexto BUSCAGLIA propõe que: 
“(...) esta pode atuar de uma forma bastante positiva como mediadora entre a sociedade em que seu filho terá de viver e o ambiente mais consciente e receptivo que ela pode the oferecer (...) cada membro da família deve adaptar seus próprios sentimentos em relação à deficiência (...) só assim a criança ajustará seus sentimentos em relação à própria deficiência e por fim a si mesma, como uma pessoa completa." (2002, p. 90)

A família é fundamental, tanto para a criança normal como para a deficiente, pois irá transmitir os valores positivos ou negativos que esta deve seguir. Assim, uma constituição saudável de família é primordial para que a criança construa uma auto-imagem positiva.

O processo de inclusão de qualquer tipo de deficiência requer um trabalho em conjunto, assim, familiares, profissionais conscientes de suas intervenções, amigos, professores, enfim, todas as pessoas que possuem contato com o indivíduo, podem melhorar sua qualidade de vida.

\subsection{Conhecendo a deficiência visual.}

DAVIDOFF (2001) caracteriza a visão como o sentido humano mais relevante, devido a grande dependência da mesma para o contato e obtenção das informações do meio externo.

Qualquer pessoa sem exceção pode nascer com a deficiência visual ou adquiri-la. A perda de visão pode ocorrer repentinamente por causa de um acidente ou de doença súbita, ou tão gradativamente que a pessoa atingida demore a tomar consciência do que está acontecendo.

Vários autores buscaram dividir a deficiência visual em dois grupos: cegueira e baixa visão ou visão subnormal.

Dentre eles, ROCHA, RIBEIRO \& GONÇALVES (apud AMIRALIAN, 1997) caracterizam baixa visão de acordo com sua intensidade, podendo ser leve, moderada, profunda, severa e perda total da visão.

Observa-se que existem vários níveis de visão subnormal. O indivíduo pode perceber vultos, luzes, possuir capacidade de leitura com ou sem auxílio óptico, enfim, é capaz de preservar resíduos da sua visão e realizar tarefas.

Assim, a baixa visão é entendida quando 0 indivíduo possui pouca percepção do que está ao seu redor. A pessoa pode enxergar o suficiente para fazer atividades do cotidiano sozinha, ou quase nada. Consegue, em geral, perceber o vulto das pessoas e sentir quando estas se aproximam sem que precisem falar.

$$
\text { Por outro lado, AMIRALIAN }
$$

(1997) ressalta que é considerado cego àquele que apresenta desde a perda da percepção luminosa até a ausência total de visão.

Essas pessoas conseguem desenvolver melhor os outros órgãos do sentido, para o seu desenvolvimento global e necessitam utilizar o sistema Braille para a comunicação da escrita.

DANGELO (1998) enfatiza que as pessoas cegas, em geral, apresentam 
uma lesão no lobo occipital e/ou no nervo óptico, que se localiza no córtex cerebral, sendo que $o$ primeiro responde pelo processamento das informações visuais e o segundo é responsável por estas.

Portanto, a deficiência visual deve ser considerada como um problema físico que acarreta em dificuldades no desenvolvimento do indivíduo devido à importância deste órgão sensorial.

\section{METODOLOGIA}

\subsection{Descrição do público-alvo}

A efetivação do trabalho ocorreu em uma sala da instituição, participaram do grupo em média 12 deficientes visuais com idade entre 30 a 70 anos, de ambos os sexos. No total, foram realizados 24 encontros, sendo que estes ocorriam semanalmente.

A maioria dos deficientes pertencia a famílias de baixa renda, sendo que alguns residem na própria associação, por não terem contato com a família. Em geral, não completou o $1^{\circ}$ grau e não trabalham.

\subsection{Os Materiais Utilizados}

Para a preparação do trabalho com a demanda em questão e realização dos objetivos propostos com os deficientes visuais, foram selecionados materiais bibliográficos e de natureza diversas como (cadeiras, som, papéis, tecidos, instrumentos musicais, objetos variados para reconhecimento, dentre outros) com várias texturas e formas e alimentos diferenciados, para que fossem discriminados pelo grupo.

\subsection{Procedimentos}

Após a apresentação da proposta de intervenção a ser realizada com o grupo, as estagiárias consideraram os seguintes fatores: disponibilidades de dias, horários e faixa etária. Para tanto, realizou-se um levantamento nos prontuários dos usuários.

A seguir, foi realizada uma reunião com os interessados no intuito de apresentar a proposta do trabalho e fechar um contrato inicial. Posteriormente discutiuse com a supervisora do estágio e com a psicóloga da instituição, as possíveis atividades a serem desenvolvidas.

A continuidade do estágio consistiu em supervisões antecedendo aos encontros $\mathrm{e}$ as atividades que seriam trabalhadas com o grupo.

Foram selecionadas atividades que tinham como foco desenvolver $e$ trabalhar os seguintes aspectos:

- Estimulação da percepção tátil através de identificação de texturas e formas.

- Estimulação da oralidade: com minicurso de oratória ministrado por professora especializada.

- Autonomia através de discussões abordando as questões afetivas e treinamento da mobilidade física.

- Memórias auditivas, gustativas, olfativas e táteis aguçando estes sentidos utilizando musicas, alguns tipos de alimentos, objetos orgânicos e inorgânicos.

- Esquema corporal com exercícios de psicomotricidade, caminhadas, danças, gincanas e brincadeiras. 
- Promoção da integração e cooperação a partir de dinâmicas, discussões e trocas de experiências.

- Estimulação da escuta por meio de discriminação de sons, músicas, dentre outros.

- Expressão de sentimentos através de desenho livre, trabalhos com argila, leitura de poesia, jogo de palavras, dinâmicas de relaxamento e vivências.

- Debate e discussão dos seguintes temas: preconceito, inclusão social, sexualidade, direitos e deveres, talentos, dentre outros.

- Incentivo a produção: através do plantio de mudas de hortaliças, contato com natureza.

Essas, dentre outras atividades visaram à melhoria na qualidade de vida dos deficientes visuais.

\section{RESULTADOS E DISCUSSÃO}

Sobre as condições de desenvolvimento das pessoas deficientes ou não VAYER e RONCIN (1989, p. 28-29) afirmam o seguinte:

"O indivíduo deficiente constrói sua pessoa com suas possibilidades, isto é, os dados originais e as estruturas corporais. Essa construção de sua pessoa e de seu conhecimento do mundo é sempre uma autoorganização que 0 meio ambiente, sobretudo o das pessoas pode facilitar ou não. (...) As condições de um desenvolvimento harmonioso são sempre, quer 0 indivíduo seja deficiente quer não, vinculadas ao meio que fornece ao sujeito os sentimentos de segurança, de poder agir e de ser autônomo."

Os objetivos dos encontros na instituição foram, dentre outros, oferecer oportunidade para que os deficientes visuais pudessem melhorar seu desenvolvimento e capacidades em diversos aspectos. Durante os encontros, as estagiárias agiram como facilitadoras das atividades aplicadas. Para isto, houve a preocupação de oferecer uma aprendizagem significativa, ou seja, condizente com o conhecimento obtido pelo grupo.

Foram realizadas atividades motoras, que desempenharam o papel de estimular os outros órgãos do sentido dos usuários e que são fundamentais para melhorar a interação do deficiente visual com o meio externo. Além disto, os temas propostos para discussão: direitos e deveres, preconceito, estigma, inclusão e integração, dentre outros, foram de grande valia, para suscitar a conscientização dos participantes em relação ao seu lugar na sociedade, também melhoraram o autoconceito e auto-estima dos participantes.

Com certeza o trabalho realizado conseguiu proporcionar um ambiente rico e estimulador visando o bem-estar dos deficientes visuais e sua evolução. Os resultados obtidos nos encontros permitiram concluir que 0 trabalho desenvolvido pelo grupo de estagiárias foi alcançado com êxito.

A partir das atividades propostas, foi observada uma grande evolução de aprendizado dos deficientes visuais. Durante as atividades estes, tiveram a 
possibilidade de explorar todas as suas potencialidades. Foi dada a liberdade de participação do grupo para propor atividades nos encontros, mas poucos 0 fizeram.

Os encontros, também colaboraram, para que o grupo se conscientizasse sobre o seu papel na luta pela inclusão social.

Devido à baixa escolaridade de alguns membros percebemos certa dificuldade, em algumas tarefas propostas.

Entretanto, foi notória a melhora dos integrantes do grupo no decorrer dos encontros, visto que estes demonstraram uma melhora na auto-estima, na comunicação, na participação, no desenvolvimento das atividades, no pensamento crítico, enfim no desenvolvimento global como podemos verificar pelos depoimentos de alguns usuários:

N., cego, 33 anos: "Gostei muito dos encontros, as atividades foram bem diferentes e os temas de discussão importantes".

R., cega, 50 anos: "As estagiárias conduziram bem o grupo, me senti a vontade para participar e gostei muito dos temas discutidos, principalmente sobre inclusão social".

S., baixa visão, 45 anos: "Aproveitei bem os encontros foi uma experiência muito especial".

No total foram realizados 30 encontros com atividades bem diversificadas. Com o passar do tempo, houve um aumento do número de participantes e uma maior motivação para os encontros. Assim, ficou explícito o aspecto positivo dos encontros, bem como, o alcance dos objetivos propostos.

Para a caracterização do nível sócio-econômico foram levantados dados dos usuários na secretaria da instituição. Estes podem ser observados pela descrição e gráficos que se seguem:

O grupo contou com a participação de até 15 usuários com idade entre 30 e 55 anos. Sendo 9 homens e 6 mulheres, destes 5 possuem baixa visão e 10 são cegos, 5 moram na Associação e 10 com suas famílias, 2 trabalham e ganham salário mínimo, 5 concluíram o $1^{\circ}$ grau, por fim todos possuem um nível econômico baixo.

Gráfico 1. Estudo Sócio Econômico

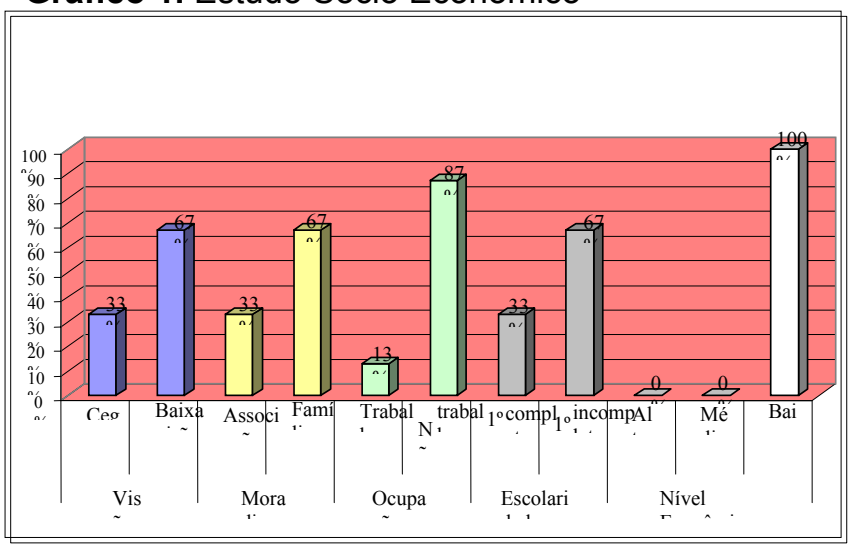

\section{ALGUMAS CONCLUSÕES}

"Mudar é um ato simples, ainda que seja possível complicá-lo de muitas maneiras. A gente complica 
a mudança, achando que ela vai acontecer porque ela é desejada. Isto nem sempre é verdadeiro e raramente dá certo. Mais importante que o desejo é o comprometimento com a mudança”.

SHINYASHIKI (1998, p. 153)

Para que a mudança ocorra de fato e passemos da integração a inclusão, são necessárias a conscientização da existência do problema e a ação para que este seja solucionado.

Segundo MACIEL (2000) a ignorância social colabora para a valorização das limitações que a deficiência acarreta. Assim, esta passa a ser um fardo pesado para a sociedade. O preconceito ainda é muito intenso, o que leva a pessoa portadora de qualquer tipo de deficiência a ser rotulada de incapaz, indefesa e/ou sem direitos. Faz-se necessária muita persistência e esforço para superar esta situação.

WERNECK acredita que:

“(..) o problema não é a deficiência em si, mas a piedade e o preconceito da sociedade (...) essas reações nada mais são do que o fruto da ignorância, ou melhor, da falta de formação. $A$ falta de formação é um processo silencioso, lento, progressivo e cumulativo de noções inadequadas sobre temas-tabu como a deficiência. A falta de formação é o alicerce do preconceito e afasta as pessoas da realidade." (2000, p.144).

A pessoa que nasce ou adquire um problema físico ou mental, serão mais limitados pelas reações da sociedade do que pelo seu próprio problema. Em geral, é a sociedade que define o deficiente como incapaz, e é a pessoa que sofre as conseqüências deste tratamento.

Desta forma, a busca do conhecimento e informações sobre a deficiência é o primeiro passo para que ocorra de fato a inclusão social e o preconceito cesse. Infelizmente, as pessoas com qualquer tipo de deficiência ainda vivenciam uma realidade marginalizada e excluída e esta só poderá transformada por meio da conscientização e educação. A imagem que a sociedade possui de pessoas portadoras de deficiência, encontra-se cristalizada e distorcida, sendo necessária uma mudança de valores e de paradigmas. A autonomia e a inclusão social só acontecerão se houver uma mudança profunda nos padrões e valores sociais.

De todo o exposto neste artigo, infere-se que é necessária a continuidade deste trabalho, pois a estimulação proposta nas atividades é de grande valia para o desenvolvimento global dos deficientes visuais. Desta forma, a estimulação é uma ferramenta poderosa neste contexto, assim é interessante à continuidade e ampliação deste trabalho. Sugere-se que outros projetos e pesquisas aconteçam para fortalecer essa categoria de pessoas, bem como enriquecer a área com novas propostas de trabalho.

O papel da instituição onde foi realizado o trabalho prático é primordial visto que colabora para a amenização do sofrimento do portador de deficiência e das diferenças sociais, proporcionando um suporte emocional e psicológico. 


\section{AGRADECIMENTOS}

Aos funcionários e a todos os usuários da Associação Filantrópica de Proteção aos Cegos de Presidente Prudente.

Aos colegas estagiários que iniciaram o projeto e os que ainda estão desenvolvendo o mesmo.

\section{REFERÊNCIAS BIBLIOGRÁFICAS}

AMIRALIAN, M. L. T. M. Compreendendo o Cego: uma visão psicanalítica da cegueira por meio de desenhos-estórias. São Paulo: Casa do Psicólogo, 1997.

AMIRALIAN, M. L. T. M. Psicologia do Excepcional. São Paulo: EPU, 1986.

ASSUMPÇÃO, J. e SPROVERI, F. Introdução ao Estudo da Deficiência Mental. São Paulo: Menon, 1991.

BUSCAGLIA, L. F., Trad. MENDES, R. Os deficientes e seus pais: um desafio ao aconselhamento. $4^{a}$ ed., Rio de Janeiro: Record, 2002.

COLEMAN, J. A Psicologia do anormal e a vida contemporânea. São Paulo: Pioneira, 1969.

DANGELO, J. C.; FANTTINI, C. A. Anatomia humana Básica. São Paulo: Atheneu, 1998.

DAVIDOFF, L. Introdução à Psicologia. $3^{\mathrm{a}}$ ed. São Paulo: Makron Books, 2001.

FOUCAULT, M. História da Loucura. São Paulo: Perspectiva, 2002.
FRITZEN, S. J.; Dinâmica de Recreação e Jogos. Petrópolis: Vozes, 2003.

JALOWITZKI, M. Vivências Para Dinâmica de Grupos: A Metamorfose do Ser em 360 Graus. São Paulo: Madras, 2004.

MACIEL, M. R. C. Portadores de deficiência: a questão da inclusão social. São Paulo Perspec. [online]. abr./jun. 2000, vol.14, no.2 [citado 21 Dezembro 2005], p.51-56. Disponível na World Wide Web: $<$ http://www.scielo.br/scielo.php?script=sci_ arttext \&pid=S0102-

$88392000000200008 \&$ lng=pt\&nrm=iso>. ISSN 0102-8839.

MUCCI, P. R.; GALHARDO, R. A.; BELFORT, $R$. et al. Influência da orientação psicológica na fidelidade ao tratamento em portadores de glaucoma crônico simples. Arq. Bras. Oftalmol. [online]. jan./fev. 2002, vol. 65, n. 1 [citado 18 Maio 2003], p. 65-70. Disponível na World Wide Web: http://www.scielo.br/scielo.php?script=sci_a rttext\&pid=S000427492002000100012\&lng=pt\&nrm=iso. ISSN0004-2749. Acesso em: 18 maio 2003.

ROSADAS, S. C., Educação teorias e práticas pedagógicas de deficiência mental. Vitória: UFES, 1994, p. 9-35.

SASSAKI, R. K. A mídia: seu papel de aliado pró-inclusão de pessoas com deficiência na sociedade brasileira. Jul., 1999. Acesso em: <http://www.educacaoonline.pro.br/art_a_m idia.asp?f_id_artigo=66> Disponível em: jun., 2005. 
SASSAKI, R. K. Inclusão: Construindo uma sociedade para todos. RJ: WVA, 1997.

SERRÃO, M., BALEEIRO, M. C. Aprendendo a Ser e a Conviver. São Paulo: FTD, 1999.

SHINYASHIKI, R. A carícia essencial: uma Psicologia do afeto. $136^{\circ}$ ed. São Paulo: Gente, 1998.

TELFORD, C, e SAUREY, G. O indivíduo excepcional. $5^{\mathrm{a}}$ ed. Rio de Janeiro: Guanabara, 1988.

TRUGILlO, R. C. A. Psicologia da diferença. São Paulo, set. 2000. Disponível em:

$<$ http://www.bengalalegal.com/cegos.php> Acesso em: 21, jul., 05.

WERNECK, C. Ninguém mais vai ser bonzinho na sociedade inclusiva. Rio de Janeiro: WVA, 2000.

VAIER, P. \& RONCIN, C. A Integração da Criança Deficiente. São Paulo: Manole, 1989. 